\title{
Aplicação de dispositivos estratégicos em Design Social no fortalecimento de identidade local
}

\author{
Strengthening local identity through Social Design strategic \\ interventions
}

SILVA, Anna Lúcia S. V.

Universidade Federal do Ceará - UFC I lilu@dau.ufc.br

OLIVEIRA, Emilio Augusto Gomes de

Universidade Federal do Ceará - UFC I emiliodesign@gmail.com

QUEIROZ, André Carvalho de Lima

Universidade Federal do Ceará - UFC I andrecq@design.ufc.br

CAVALCANTE, Letícia dos Santos

Universidade Federal do Ceará - UFC I scavalcanteleticia@gmail.com

CARNEIRO, Alexander

Universidade Federal do Ceará - UFC I alexanderccarneiro@gmail.com

\begin{abstract}
Resumo
O artigo trata de uma pesquisa aplicada na elaboração participativa de dispositivos estratégicos de design. O objetivo é o fortalecimento da identidade local de uma comunidade no bairro Pacheco, Caucaia, Ceará. Com uma demanda da associação de moradores em um contexto de vulnerabilidade econômica e precariedade ambiental na comunidade, o laboratório dá início a um processo de proposições e metodologias colaborativas, engajando a comunidade no reconhecimento de seu espaço e no resgate de sua história. São desenvolvidos dois dispositivos principais: o resgate da história do bairro, elaborado com os moradores mais antigos e um jogo colaborativo cujo tabuleiro é o bairro. Como resultado, pode-se verificar um crescente engajamento dos moradores à associação e a valorização de sua cultura.
\end{abstract}

Palavras Chave: Dispositivos estratégicos. Design social. Identidade local.

\section{Abstract}

This paper describes an applied research on the participatory development of strategic design interventions. The goal is to strengthen the local identity of a neighborhood in the city of Caucaia, Ceará. The local residents' association detected a need for a design intervention concerning persons in a context of economic and environmental vulnerability. In order to bridge this gap, the Social Design laboratory developed collaborative interventions and methodologies, engaging the community in a process of recognition of their space and recovery of their history. Two main interventions were designed: the recovery of the neighborhood's history, conducted with the help of the oldest residents, and a collaborative game, which used the map of the neighborhood as the game board. As a result, it is possible to verify a growing involvement of residents with the association and a process of cultural valorization.

Keywords: Strategic interventions. Social Design. Local identity. 


\title{
1 CONTEXTO E FUNDAMENTOS
}

As propostas do laboratório promovem iniciativas em design social, que tratam de situações locais e de pessoas, com hábitos e empenho, no enfrentamento do cotidiano. Proposições colaborativas implicam na produção de um tipo de redescoberta dessas pessoas de seu próprio potencial e capacidade de resolver problemas. O design entra como um meio capaz de facilitar novas organizações e pontos de vista da comunidade em relação a si mesma. Manzini (2017, p. 17) atribui aos especialistas em design uma parte ativa nessa redescoberta, pois são: "promotores da mudança social, uma vez que colaboram ativamente na criação das condições que a facilitam."

Uma temática que permeia a fundamentação do trabalho em questão é a inovação social enquanto metodologia para o desenvolvimento das atividades realizadas no projeto desenvolvido de 2016 a 2018 no bairro Pacheco, em Caucaia. Em seu livro, Design Estratégico para a Inovação Cultural e Social, Karine de Mello Freire define esse termo da seguinte maneira:

\begin{abstract}
Considera-se aqui como inovação social uma inovação de natureza bottom-up capaz de responder às necessidades da sociedade de hoje, de gerar mudanças duradouras e de melhorar problemas sociais amplos através de uma mudança no tecido social e de uma reorganização do existente. Nela as pessoas interessadas participam do processo e são capacitadas por ele, permitindo, assim, a redistribuição do poder de decisão da sociedade. Portanto, ao considerar o contexto de vida cotidiano, as inovações sociais são inovações que têm potencial de permitir a uma comunidade solucionar um problema e gerar novas oportunidades por meio de uma nova organização dos recursos locais. (FREIRE, 2015, p. 44)
\end{abstract}

De maneira análoga a esse pensamento, o conceito é apresentado no livro The Open Book of Social Innovation (2010) de Robert Murray, Julie CaulierGrice e Geoff Mulgan dessa forma:

Definimos inovações sociais como novas ideias (produtos, serviços e modelos) que atendem necessidades sociais e, ao mesmo tempo, criam novas relações ou colaborações sociais. Em outras palavras, são inovações que são boas para a sociedade e também ampliam sua capacidade de ação. (MURRAY; GRICE; MULGAN apud MANZINI, 2017, p. 25).

A inovação social, portanto, pode ser compreendida como um caminho para o desenvolvimento de estratégias participativas que visam transformações 
sociais positivas e sustentáveis. Nesse sentido, o designer pode ser um agente capaz de contribuir significativamente na construção dessa nova realidade. Para Freire (2015, p. 176), ao fazer parte desse processo ativamente o designer é capaz de "articular os diferentes ecossistemas, identificar potencialidades, fragilidades, oportunidades ou ameaças, mapeando o contexto e as tendências; projetando, por fim, cenários". Esse papel de mediador e articulador exercido pelo designer faz parte de um processo conhecido como design estratégico, que é, segundo Freire (2015, p. 30) "uma prática projetual desenvolvida a partir da identificação das competências distintivas da organização e da identificação de oportunidades existentes no atual ambiente". Nesse sentido, o design estratégico se coloca como uma prática fundamental para a eficácia de projetos de inovação social, pois pressupõe uma abordagem metodológica compatível e coerente com as problemáticas a serem enfrentadas, de acordo com o que afirma Freire:

\begin{abstract}
A compreensão das problemáticas sociais, a interação conjunta e participativa com diferentes atores, a emancipação e a habilitação dos atores envolvidos fazem do design estratégico um recurso privilegiado do design para favorecer processos de inclusão, acesso e participação no âmbito social e para ressignificação dos espaços urbanos. (FREIRE, 2015, p. 48).
\end{abstract}

Partindo desse pensamento e prática inclusiva e com o objetivo de construir um cenário almejado pelos envolvidos no projeto, o designer faz uso de diferentes estratégias, como por exemplo o desenvolvimento de artefatos, serviços, sistemas e experiências e cultura com o intuito de permitir o avanço dos projetos de qualificação dos participantes e de seus contextos de vida. (FREIRE, 2015).

Dispositivos estratégicos, quando utilizados no design com objetivo de inovação social, categorizam-se como produtos de design (artefatos, peças gráficas impressas e digitais, etc) que, aliados a metodologias de co-design, tornam-se capazes de fomentar a identidade local. Fortalecer o sentido de pertencimento e a autonomia de comunidades é o objetivo principal da aplicação destes dispositivos na pesquisa.

O conceito contemporâneo do design como criador de discursos soma-se ao design de inovação social para criar planejamentos que ocasionam um impacto muito mais profundo do que a realização do projeto por si só. Os dispositivos estratégicos, bem como as metodologias co-criativas para sua elaboração, quando postos em prática, fazem parte de um conjunto de iniciativas aliadas, cujo objetivo central é o de construir um discurso através do design que seja capaz de reverberar uma mensagem/objetivo, em oposição à uma mera constituição física ou realização de produtos. Krippendorf diz que: 
O discurso do design é o tipo de fala que desenvolve nossos futuros modos de vida dentro do mundo material. [...] Através da linguagem negociamos e aceitamos deveres e narramos o futuro em que nossas intenções se tornarão reais. Através da linguagem organizamos equipes, defendemos nossas ideias, e estimulamos stakeholders a formar redes que podem levá-los à realização. (KRIPPENDORF, 2000, p. 92).

O propósito final não é somente concretizar produtos, mas sim, fomentar uma dinamicidade e inquietação de uma comunidade em relação ao seu status quo e, ainda, fazê-lo em conjunto, em um processo que envolve diversos agentes, instituições, planejamentos e ferramentas metodológicas. Esse modus operandi é importante pois, uma vez cessadas as atividades em uma comunidade, a inquietação permanece, podendo dar início a outras ações independentes, mas relacionadas. Ainda em Krippendorf (2000, p. 94): “Design é a defesa de uma causa. Onde as pessoas falam sobre o design, ele torna-se político. O design é mais efetivo quando incrustado na mesma comunidade que exige participação no futuro que ele realiza."

Os desdobramentos do design como discurso associam-se à noção de Design Centrado no Ser Humano. Os projetos realizados não somente trazem os usuários e comunidades como forças participativas, mas também guardam suas vontades e desejos como bússolas projetuais, almejando sempre entender e colocar as vontades dos moradores em primeiro lugar. O Human-Centered Design (HCD, ou Design Centrado no Ser Humano), como trazido pelo Field Guide to Human-Centered Design (IDEO, 2009, p. 5), traz noções básicas sobre o que é e como utilizar o HCD em campo. Além de "Human-Centered Design", a sigla HCD também evoca três conceitos importantes desta ferramenta: Hear (Ouvir), Create (Criar) e Deliver (Implementar): "A razão pela qual esse processo é chamado de 'Centrado no Ser Humano' é que ele começa pelas pessoas para as quais estejamos criando a solução."

"O design é uma cultura e uma prática relativas ao modo como as coisas deveriam ser a fim de alcançar as funções e os sentidos desejados. Ele tem lugar em processos abertos de codesign, nos quais todos os atores envolvidos participam de diferentes maneiras." (MANZINI, 2017, p. 68).

Em janeiro de 2016 representantes da Associação de Moradores e Amigos do Pacheco (AMAPACHECO) trazem para o laboratório a solicitação de construir sua identidade visual. A equipe se dirige ao bairro e verifica a necessidade de um levantamento mais aprofundado para entender melhor as demandas da comunidade. Com isso, nasce o projeto de pesquisa-ação e damos início a um processo participativo com o propósito de envolver os moradores no reconhecimento de sua própria história e de seu espaço. 
Um dos aspectos chave nesse tipo de abordagem é o sentido de pertencimento em relação ao ambiente, uma vez que os moradores têm a oportunidade de identificar seus valores e interesses durante o processo.

\begin{abstract}
[...] uma porção de espaço significada, ou seja, cujos fixos e fluxos são atribuídos signos e valores que refletem a cultura de uma pessoa ou grupo. Essa significação é menos uma forma de se apossar desses elementos e mais de impregnálos culturalmente para que sirvam para a identificação da pessoa ou do grupo no espaço, para que encontrem a si mesmos refletidos em determinados objetos e ações e possam, assim, guiar-se, encontrar-se e construir sua medida cultural no espaço. (DUARTE, 2002, p. 65).
\end{abstract}

Com a combinação da carga conceitual de uma visão estratégica sobre o design de inovação social, utilizamos metodologias que dão voz aos futuros usuários e tomam seus desejos como pré-requisitos, e com a constante consideração sobre o discurso que o design cria e seu impacto na comunidade, o desenvolvimento dos projetos de dispositivos estratégicos explora em várias direções o potencial do que se pensa e se faz no design atual.

\title{
2 METODOLOGIA
}

Na pesquisa são aplicadas principalmente dois tipos de metodologia: a pesquisa-ação, que pressupõe processos alternados de imersão na comunidade e desenvolvimento de projetos em sequências de constante aprimoramento; e a metodologia aplicada no laboratório que agrega à pesquisa-ação outros métodos que podem ser definidos em etapas que partem do diagnóstico da situação local, ações participativas e produção de dispositivos como veremos a seguir.

\subsection{Pesquisa-ação}

A metodologia da pesquisa-ação (TRIPP, 2005; TOLEDO; JACOBI, 2013) é aplicada de forma ampla no cenário do projeto como aprimoramento contínuo da prática das intervenções participativas, colaborativas e co-criativas, em ciclos alternados por interações e análises. Assim, as demandas do processo indicam as necessidades de dispositivos, que são realizados e aprimorados de acordo com as estratégias de ação.

A investigação-ação é um método do qual se originaram vários outros, todos alternam ciclicamente ação e análise. Tripp define a investigação-ação como: 
[...] um termo genérico para qualquer processo que siga um ciclo no qual se aprimora a prática pela oscilação sistemática entre agir no campo da prática e investigar a respeito dela. Planeja-se, implementa-se, descreve-se e avalia-se uma mudança para a melhora de sua prática, aprendendo mais, no correr do processo, tanto a respeito da prática quanto da própria investigação." (TRIPP, 2005, p. 445).

A pesquisa-ação se particulariza a partir do momento em que aperfeiçoa a prática a partir de métodos e técnicas já consagradas pela academia. Se diferencia também, pois é composta de três fases de ação, pequenos ciclos de investigação-ação que se interligam e compõe um processo maior. Na primeira, 0 problema é melhor estudado e analisado para a proposição de futuras soluções, nem sempre será trabalhado apenas com o que foi apresentado, na maioria das vezes existem mais problemas do que é inicialmente aparente. Na segunda, as soluções estudadas são postas em prática e monitoradas, para se checar seus resultados e necessidades de aperfeiçoamento. Já na terceira, os resultados são teorizados e ponderados, assim, se decide se o projeto será interrompido, se teve êxito ou se o processo será recomeçado a partir de um a nova estratégia. As três etapas são compostas por pequenos momentos de planejar, agir, avaliar e investigar e cada uma define o rumo da próxima. A reflexão e a participação permeiam todo o processo. Por meio da reflexão, a todo momento se pondera sobre como e o que será feito. Na participação, se aprimora a prática com a visão de diferentes pontos de vista sobre um mesmo objetivo durante uma experiência.

Figura 1 - Pesquisa-ação.

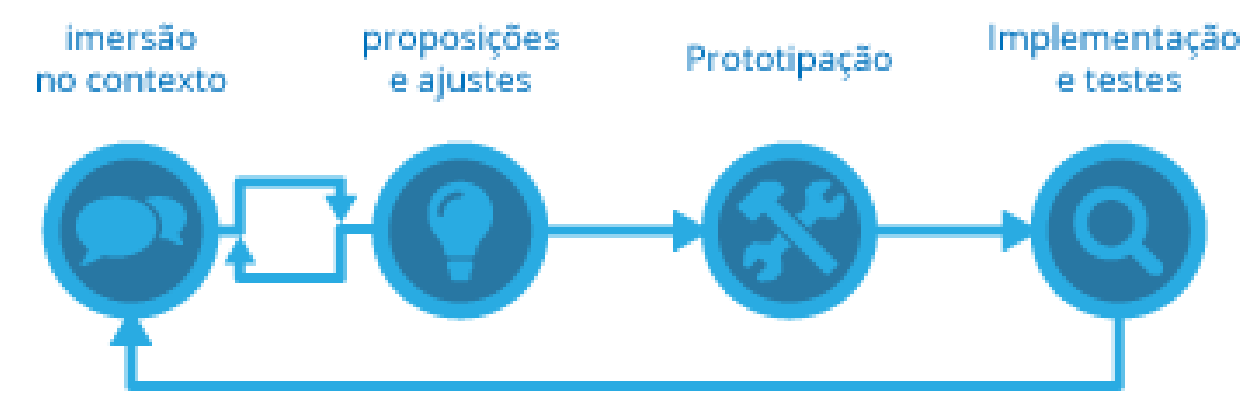

Fonte: Alexander Catunda Carneiro (2018).

Tripp (2005) classifica a pesquisa-ação em cinco diferentes modalidades:

Técnica: o pesquisador age de forma mecânica, pois ao invés de criar seus próprios métodos ele se apropria de uma prática já existente para solucionar um problema. 
Prática: o pesquisador pode escolher o que e/ou quais aspectos práticos implantar. Pode também criar quais práticas de ação, a partir de sua própria experiência.

Política: quando se quer mudar regras institucionais, cultura ou limitações políticas que restringem certas ações. Para tanto é preciso exercer poder, seja o de fazerem as pessoas trabalharem juntas, seja o de mudar as regras por si só.

Socialmente Crítica: é uma espécie de pesquisa-ação política. Existe quando regras e ações do sistema vigente são injustas e precisam ser mudadas.

Emancipatória: também é uma espécie de pesquisa-ação política. Não se restringe a provocar mudanças e beneficiar um pequeno grupo, atinge grupos sociais mais amplos com o intuito da autonomia. Esta, especificamente, é a que aplicamos nos projetos.

O sentido de pertencimento se realiza progressivamente por meio dos dispositivos estratégicos, suas aplicações e implicações. A partir dos resultados parciais obtidos na pesquisa-ação os métodos se tornam produtos das articulações que o designer opera. Entre os seus conhecimentos especializados, técnicos e as experiências vivenciais das dinâmicas cotidianas dos moradores, quando as especificidades culturais e comunitárias se revelam e são apropriadas no projeto por meio de protótipos, testes e implementações (Figura 1).

\subsection{Metodologia do laboratório}

A metodologia de trabalho do laboratório é composta por três etapas principais, que representam um percurso de desenvolvimento comum a todos os trabalhos realizados até o momento. As etapas são: i) Conectar; ii) Criar junto; iii) Concretizar (Figura 2). Na primeira etapa, se enfatiza o ato de acolher, ouvir, conhecer, conectar, visto que é o momento de verificar as demandas que são trazidas ao laboratório por representantes da comunidade que possui algum problema. É importante que a conexão ocorra por meio de imersões na situação, pois o reconhecimento da comunidade de suas próprias problemáticas é fundamental para que possam ocorrer transformações verdadeiras e duradouras por meio da participação efetiva dos moradores durante o desenvolvimento coletivo de soluções. Assim, a construção de um diagnóstico completo da situação se dá juntamente com os envolvidos. Nesse processo também são formadas parcerias, fundamentais para a proposição e execução de ações nas etapas posteriores. Após consolidado o diagnóstico, é definido o problema de projeto a partir da compreensão das demandas apresentadas e dos dados coletados. Caso necessário, são construídas novas demandas de acordo com a observação reflexiva sobre o problema que, uma vez definido, pode apontar para a formulação de novas questões. 
Figura 2 - metodologia do Varal - 3Cs - Conectar, Criar Junto, Concretizar.

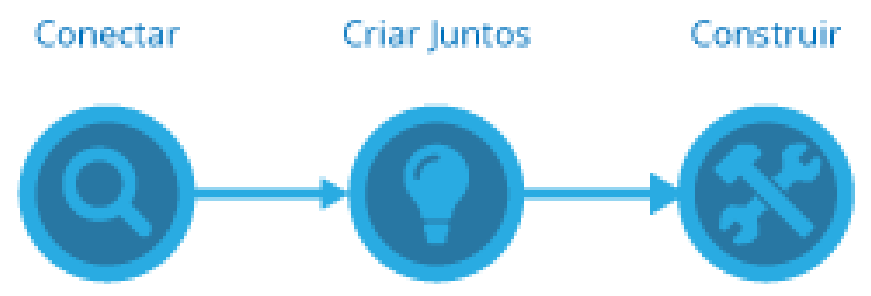

Fonte: Varal - Laboratório de Iniciativas em Design Social da UFC (2018).

A segunda etapa, criar junto, marca o início do processo de projeto dos dispositivos estratégicos e é caracterizada pela aplicação do co-design junto à comunidade para o desenvolvimento participativo de soluções. No processo de codesign (MANZINI, 2017, p. 63) o sentido de cocriação e de cooperação no processo de projeto abrange três tipos de premissas: 1- "processos altamente dinâmicos" como metodologias de construção de consenso e processos complexos interconectados, frequentemente contraditórios; 2- "atividades criativas e proativas" que abrangem iniciativas dos participantes e a criatividade como propulsora de diálogos sociais alimentados por novas ideias; 3- "atividades complexas de design" que demandam ferramentas específicas de design para tornar situações e ideias complexas tangíveis e comunicáveis (MANZINI, 2017, p. 63). É nessa etapa também que, quando oportuno, são estabelecidas pontes com disciplinas que focam na temática do Design Social no curso de Design da Universidade Federal do Ceará. Após desenvolvidos os primeiros protótipos dos dispositivos, eles são testados, aprimorados e implementados a fim de fomentar o sentido de pertencimento dentro da comunidade e aumentar a sua visibilidade perante a cidade ou a instituições que também possam colaborar de maneira positiva no processo. Em seguida, são verificadas as respostas das soluções ou o feedback gerado a partir delas. Quando necessário as soluções são recriadas até que alcancem os objetivos específicos das demandas, por meio da pesquisa ação (Figura 1).

A terceira etapa é o momento de concretizar. Nela são feitas análises críticas sobre os resultados obtidos a partir das ações realizadas e da implementação e entrega dos dispositivos junto à comunidade. Posteriormente, parte-se para uma etapa mais centrada no laboratório, na qual são feitas reflexões e produção acadêmica sobre o trabalho realizado.

\section{OS DISPOSITIVOS}

A partir dos conceitos e metodologias abordados, faremos uma análise dos dispositivos estratégicos aplicados em um projeto de Design Social e suas implicações no fortalecimento da identidade do bairro. 


\title{
3.1 Resgate histórico
}

A demanda da comunidade do bairro foi levada para a disciplina de Projeto 1 do curso no ano de 2016 e as proposições de projeto realizadas pelos alunos como conclusão da disciplina foram apresentadas na escola, onde funcionários e membros da comunidade estavam presente. Houve um feedback positivo por parte da escola, que manifestou interesse em realizar alguns dos projetos expostos pelos alunos. Paralelamente a essas ações que iniciaram seu desenvolvimento em conjunto com a escola, alguns membros da diretoria da Associação trouxeram relatos sobre a história do bairro. Porém, ao identificarmos que não havia nenhum registro dessa trajetória, iniciamos um processo de levantamento audiovisual e escrito dessas diferentes histórias dos moradores junto com o apoio dos residentes mais antigos e a suas indicações. Foram realizadas entrevistas com cinco moradores antigos: Seu Duarte, Seu Manuel, Dona Antônia, Dona Alice e Seu Francisco; e uma entrevista coletiva com as crianças da escola do bairro. Cada um compartilhou a sua visão, suas anedotas, fatos curiosos que ocorreram na comunidade e até mesmo relatos de criaturas mágicas que vagavam pelo local em tempos passados.

\begin{abstract}
Tem uma estrada aí que nesse tempo que tinha mato aí, que não tinha luz né, aparecia era uma besta fera com uma tinideira de ferro, "tiririm tiririm tiririm" correndo assim. E lobisomem tinha mesmo, uma vez um conhecido meu ia pra casa da namorada, aí ia pra praia né, aí o lobisomem atacou ele, ai ele pra se livrar entrou dentro do mar. Viam era muitos deles por aí né. Agora eu nunca vi não.
\end{abstract}

A partir desses registros brutos, iniciou-se um trabalho de edição para selecionar os trechos principais para comporem os vídeos finais de cada entrevista. Em seguida, foi realizada a transcrição a partir dos vídeos editados, o que possibilitou uma melhor compreensão e estruturação dos fatos em uma sequência cronológica. A partir dessa organização escrita, foi feita uma nova edição para unir os relatos em um único vídeo com o propósito de contar a história do bairro na visão dos próprios moradores, desde os mais antigos até os mais jovens.

Figura 3 - Contadores de história (da esquerda para a direita): Seu Francisco, Seu Duarte, Seu Manoel, Dona Alice, Dona Antônia
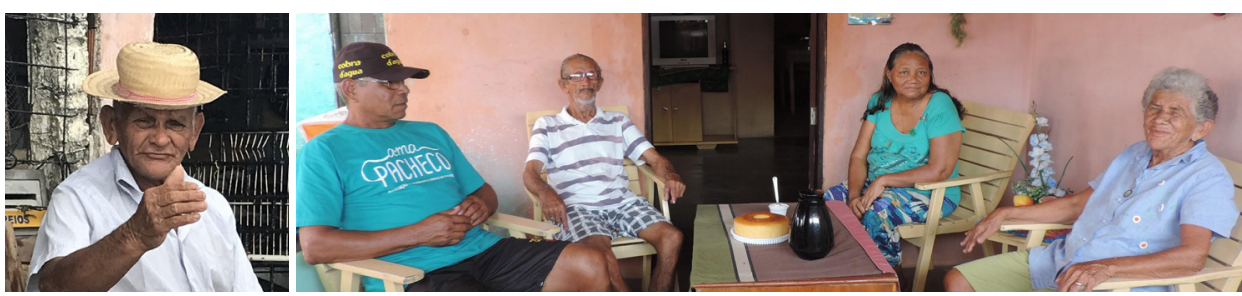

Fonte: Anna Lúcia dos Santos Vieira e Silva (2017). 
Como dispositivo resultante, o vídeo foi entregue à comunidade e exibido no mutirão de encerramento do projeto. Ele também foi publicizado na internet para ser acessado livremente neste link: (https://www.youtube.com/ watch?v=Ti7HaRtBL9k). Outros dispositivos resultantes são os pôsteres com a história que estão em processo de desenvolvimento para comporem um mural na escola. Além disso, também está sendo desenvolvido um livreto para ser distribuído de maneira mais ampla no bairro.

\subsection{Jogo}

O Jogo do Pacheco nasce a partir da proposição de um grupo de alunos da disciplina de Projeto 1 no primeiro semestre de 2016 como dispositivo estratégico para fortalecimento da identidade local. Na proposição dos alunos de design, o espaço geográfico do bairro estava representado no tabuleiro. $\mathrm{Na}$ apresentação dos projetos dos alunos na escola, é decidida a continuidade do projeto, mas recriado de forma participativa. Primeiramente, são pensadas maneiras de envolver as crianças no processo de criação do jogo, fazendo com que elas se identificassem no projeto desde o início e se sentissem parte do mesmo. Como critério para a criação do jogo, os pressupostos estabelecidos foram que o jogo fosse colaborativo e que o tabuleiro fosse o próprio bairro.

Quando foram iniciados os mutirões mensais na escola Adriano Martins, a turma do 5 ano do ensino fundamental foi a que mais se engajou no desenvolvimento do projeto. Na primeira metodologia participativa é realizada uma gincana com os alunos. Em uma sala de aula, os alunos falam sobre os jogos que conhecem e quais são seus favoritos, dão ideias sobre quais componentes gostariam que o Jogo do Pacheco possuísse, iniciando uma votação para apurar os componentes preferidos pela turma. Os componentes de jogo mais votados foram: Bila, cartas, dado, peão. Verificamos que ao receber informações através de uma atividade como essa, é de extrema importância estar verdadeiramente aberto às possibilidades de resposta.

Depois da gincana do voto, as crianças iniciam a atividade de ilustração com canetinhas, papel e tecido. Os lugares e atividades que elas desenham são posteriormente usados como base das informações temáticas e de identidade do dispositivo. O processo se enriquece ao admitir informações de pessoas com outras experiências. O componente "bila" (ou bola de gude, uma esfera de vidro pequena usada em muitas brincadeiras) muito dificilmente teria sido concebida pelos designers projetistas, justamente por já terem suas ideias referenciais sobre elementos clássicos de jogos bastante definidas. A ideia da bila é muito bem abraçada pela equipe, e é transformada no principal componente do jogo.

Inicia-se então a fase de pensar no jogo em si, tendo como inspiração e direção os componentes votados pelas crianças. Os requisitos para o projeto 
do jogo foram os seguintes: 1- proporcionar o reconhecimento e a valorização da comunidade pelas crianças; 2- ser simples; 3 - ter as bilas como elemento principal: 4- envolver destreza.

\section{Proporcionar o reconhecimento e a valorização da comunidade} pelas crianças é o principal objetivo dos dispositivos estratégicos utilizados na inovação social. No jogo, o reconhecimento foi gerado desde a participação das crianças no projeto, dando o pontapé inicial, até a utilização dos próprios desenhos das crianças posteriormente aplicados no tabuleiro e nas cartas. Os locais do tabuleiro e os personagens foram escolhidos e colocados a partir da frequência com que estes apareciam nos desenhos e textos dos alunos.

Ser simples é essencial tanto para a proposta quanto para a faixa etária envolvida. Para crianças de oito a catorze anos é importante uma objetividade na proposição de realizar tarefas, mesmo para brincar ou jogar. Assim também, podem manter-se interessadas e entretidas com uma única função durante um curto tempo, O dispositivo possui poucas regras e há o esforço para mantê-las o mais intuitivas quanto possível.

Ter as bilas como elemento principal nasceu da proposta das crianças, que a votaram majoritariamente como elemento do jogo. Pela enorme criatividade que a escolha desse objeto provoca e pelas diversas possibilidades inexploradas da bila em um jogo de tabuleiro $A$ escolha desse componente suscitou outro requisito: usar as bilas no tabuleiro da mesma forma com que as crianças jogam na rua.

Envolver destreza se mostrou um caminho eficaz não só para assegurar as regras claras, mas também para ajudar a manter as crianças jogadoras focadas numa atividade que é tanto mental quanto física.

O primeiro protótipo (Figura 4) foi executado em uma folha de isopor de cerca de $2 \mathrm{~cm}$ de espessura e utilizando cerca de aproximadamente 20 bilas de diferentes cores e tamanhos. Os nomes dos locais do bairro estavam colados com papel nos locais indicados no tabuleiro. O protótipo foi levado para testes com as próprias crianças, que jogaram diversas partidas e se mostraram empolgadas. Várias observações foram feitas, tanto por monitores quanto pelos próprios jogadores, que deram sugestões sobre os locais escolhidos, mostrando que alguns eram mais apropriados que outros. Após o primeiro teste, verificou-se a necessidade de deixar as partidas mais dinâmicas, aumentar a rejogabilidade para deixar o jogo com um constante ar de novidade.

Mais dois protótipos foram desenvolvidos e testados diversas vezes em vários mutirões. O conjunto de regras, as combinações de jogadores, os ambientes, os níveis de instrução das regras e componentes variaram em cada 
SILVA, Anna Lúcia S. V. et al.

teste. As variações foram determinadas por observações feitas sobre o tempo das partidas, a aceitação e entendimento das regras, e os níveis de interesse e participação das crianças enquanto jogavam.

Figura 4 - O primeiro protótipo.
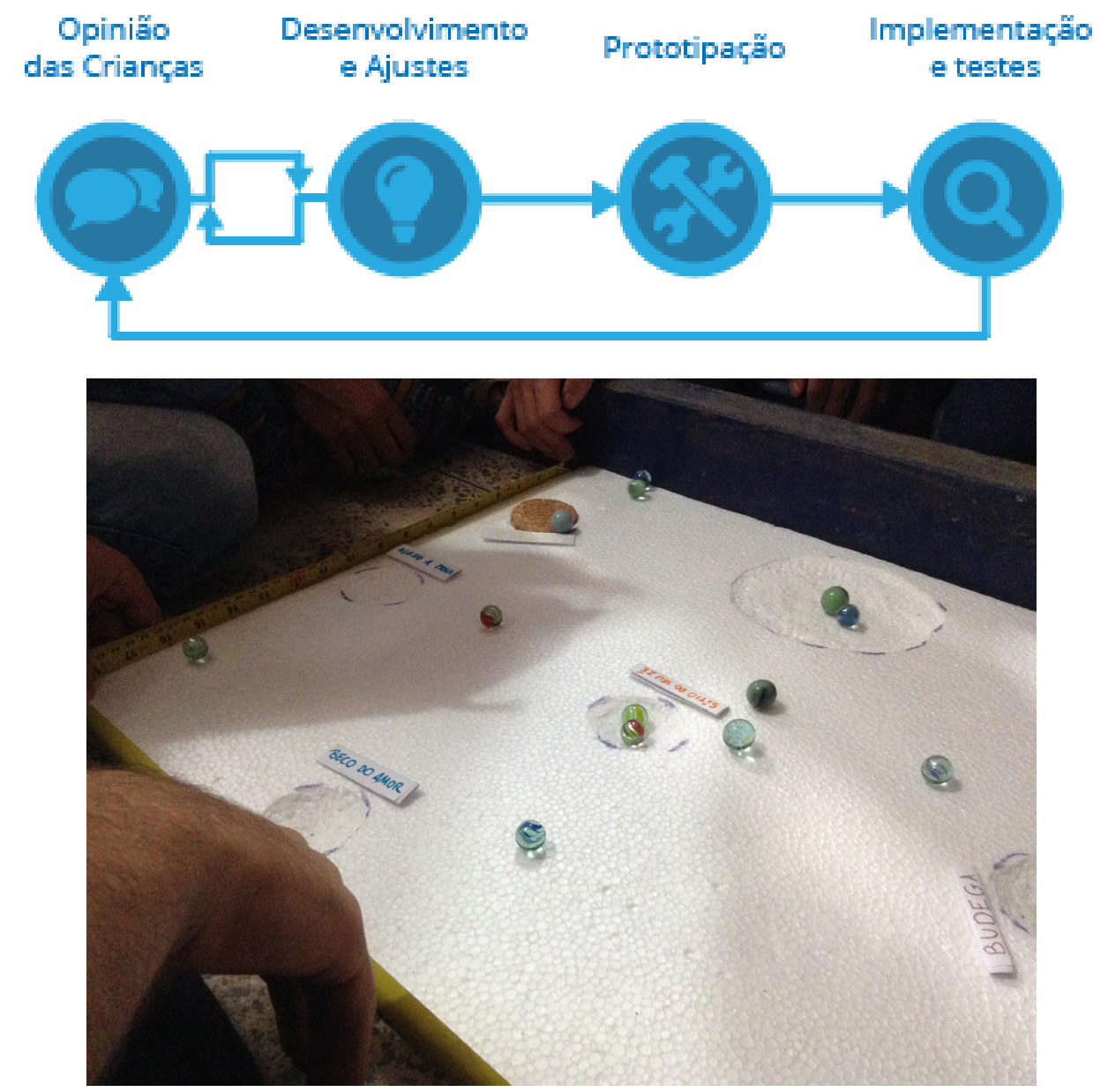

Fonte: Anna Lúcia dos Santos Vieira e Silva (2017).

Figura 5 - O segundo protótipo.

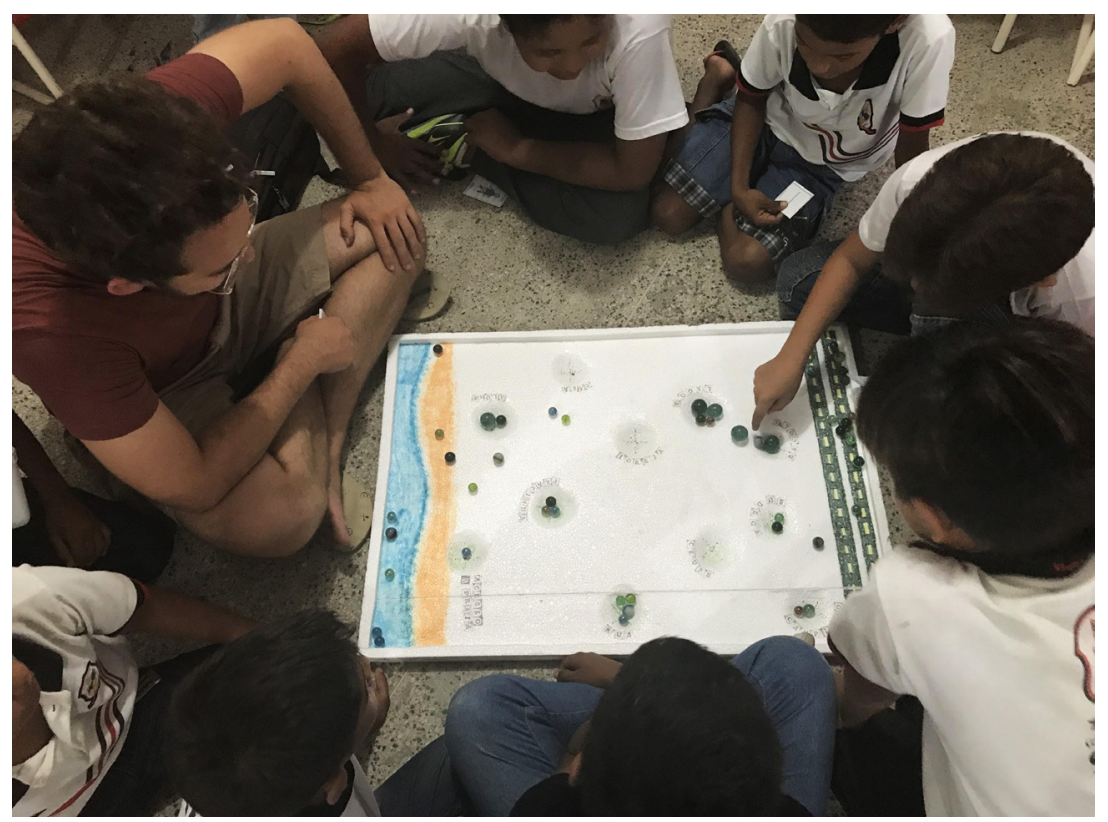

Fonte: acervo pessoal (2017). 
O modelo definitivo do jogo (Figura 6 ) foi produzido em uma chapa de compensado de $84 \times 59 \mathrm{~cm}$ (medidas de uma folha A1) e $3 \mathrm{~mm}$ de espessura, com 11 circunferências de $6,5 \mathrm{~cm}$ de diâmetro cortadas a laser e revestidas com tecido elástico, para conter as bilas. O cenário do tabuleiro foi impresso a laser em vinil e colado em cima da madeira, cujo as circunferências já estavam revestidas de tecido. Esta impressão é composta por ilustrações criadas à partir do trabalho de tecido das crianças. Acompanham também 4 cercaduras de 6 $\mathrm{mm}$ de espessura e $4 \mathrm{~cm}$ de altura cada para impedir que as 24 bilas escapem, 14 cartas de ação, 8 cartas de personagem 11 tampas para os locais e 1 manual de instruções. Como ato final, é feita uma partida inaugural com os alunos e, então, o jogo é doado para a escola.

Figura 6 - O protótipo final.

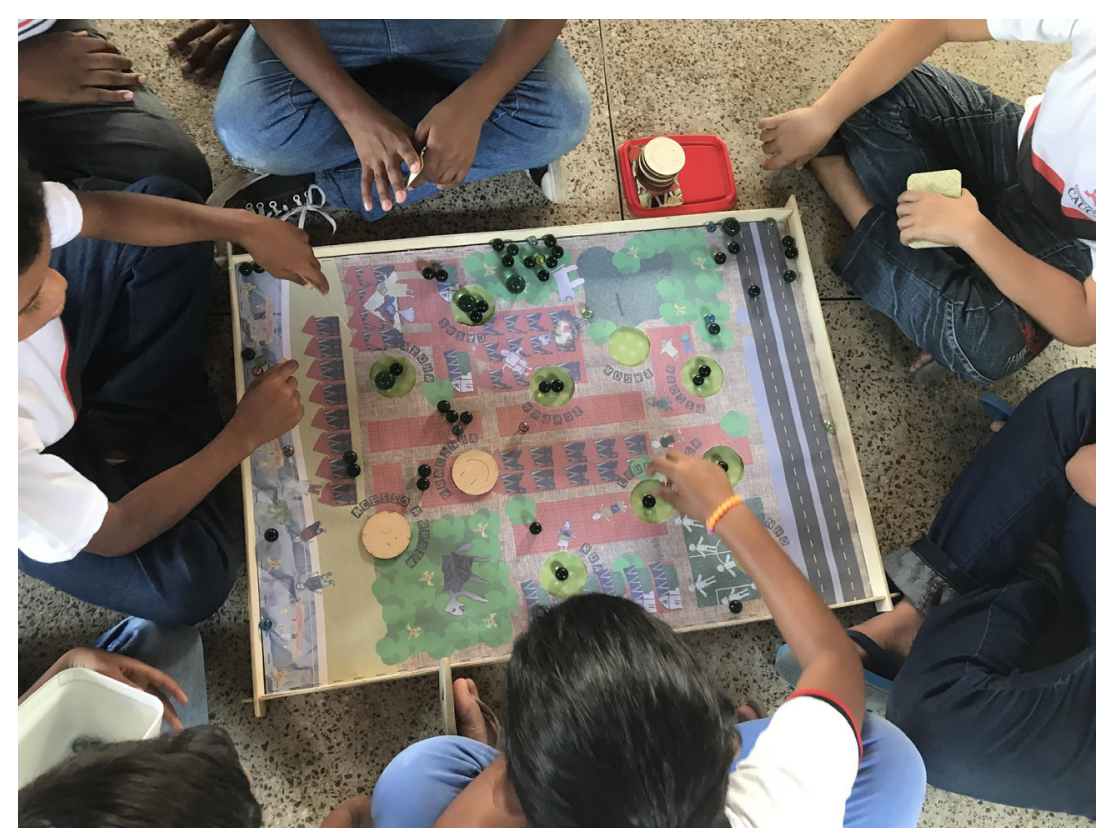

Fonte: Anna Lúcia dos Santos Vieira e Silval (2017).

Os dispositivos estratégicos são mecanismos utilizados com o objetivo de alcançar uma meta da forma mais adequada e eficaz possível. Quando aplicados no Design Social em um contexto de fortalecimento de identidade local eles operam no direcionamento das ações, na apresentação das propostas e dos processos, no envolvimento e participação da comunidade, na divulgação das atividades e contribuem para o fortalecimento da identidade. Assim, podemos considerar os dispositivos estratégicos como responsáveis por transformar a maneira que os participantes percebem seu ambiente e sua cultura.

Com a atuação participativa dos moradores, da associação e dos alunos da escola na criação dos dispositivos estratégicos, o sentido de pertencimento é assimilado durante a realização do projeto. Dessa forma, a identidade local passa a ser valorizada e os meios para que haja uma continuidade do processo, preservados com um nível favorável de sustentabilidade e inovação social. 


\section{CONCLUSÃO}

Como resultados temos três aspectos principais a considerar. $\mathrm{O}$ primeiro, de difícil mensuração, diz respeito aos efeitos das interações humanas entre a equipe do laboratório, os contadores de história, a diretoria da associação de moradores, os funcionários da escola. Cada grupo envolvido no projeto consolida suas relações internas também. São aportes sensíveis, de partilha de vida, que podem representar vínculos permanentes e referência no porvir de novas interações. A experiência sensível se evidencia nos afetos de convivência e seus rastros se integram a cada indivíduo de uma forma única por meio dos conhecimentos compartilhados e do aprendizado proporcionado pelo processo.

O segundo resultado, mais fácil de ser verificado, pode ser identificado em mudanças tangíveis: a realização dos dispositivos, entregues à comunidade; a prefeitura, uma das parceiras do projeto, passa a olhar para o bairro, fazer a coleta regular do lixo, reformas na escola e se abre aos diálogos com a associação; o projeto também contemplou a realização de outros dispositivos que não foram analisados no artigo, como a identidade visual da associação e da escola, uma horta comunitária, um ponto de ônibus e diversos mapeamentos entregues à prefeitura.

O terceiro aspecto diz respeito ao objetivo principal do projeto, o fortalecimento da identidade local. Este sentido perpassa a valorização pessoal e social. Notamos principalmente nos contadores de história e nas crianças, um tipo de estima diferenciada por se sentirem capazes de realizar os dispositivos, e reconhecer sua importância e abrangência. Os alunos demonstraram nos testes dos protótipos um reconhecimento de lugares e personagens do bairro no tabuleiro, trazendo para o jogo a maneira como se relacionam com esses espaços e os significados particulares de suas realidades. Além disso, ao receberem o protótipo final, eles perceberam no tabuleiro as ilustrações produzidas por seus colegas e a contribuição deles em cada etapa do processo para a materialização daquele artefato. Na exibição do vídeo, os contadores de história presentes compartilharam a sua satisfação ao verem e ouvirem os seus relatos serem apresentados para a comunidade pela primeira vez, propagando uma história que estava com eles e corria o risco de ser esquecida. Eles se sentiram valorizados e tiveram a importância de seu papel reconhecida pelos presentes.

A universidade, especialmente a pública, possui o compromisso de atuar na cidade e ensinar que a cidade somos nós. Temos responsabilidades sobre ela e sobre a sua construção diária. Precisamos realizar tudo o que estiver no nosso alcance para esse compromisso seja o cerne de nosso ideal, de nossas 
ações, do que acreditamos que pode vir a ser. Entendemos que o fio que nos conecta perpassa realidades muito distintas, a nossa, a da escola, dos bairros, dos moradores do Pacheco. Este fio entrelaça espaços, seres-humanos, ações e modos de viver. E é a costura o que precisamos realizar, de maneira colaborativa, por um compromisso com nós mesmos. 


\section{REFERÊNCIAS}

DUARTE, F. Crise das matrizes espaciais: arquitetura, cidades, geopolítica e tecnocultura. São Paulo: Perspectiva, 2002.

FREIRE, Karine de Mello. Design estratégico para a inovação cultural e social. São Paulo: Kazua, 2005.

IDEO. Design Kit: the human-centered design toolkit. EUA: IDEO, 2009. Disponível em: <http://www.ideo.com/work/human-centered-designtoolkit/>. Acesso em: 13 jul. 2013.

KRIPPENDORFF, Klaus. Design centrado no ser-humano = human-centered design: uma necessidade cultural $=$ a cultural necessity. Estudos em Design, Rio de janeiro, v. 8, n. 3, p. 87-98, 2000.

MANZINI, Ezio. Design: quando todos fazem design, uma introdução ao design para inovação social. Tradução Luzia Araujo. São Leopoldo, RS: Ed. Unisinos, 2017.

TOLEDO, Renata Ferraz; JACOBI, Pedro Roberto. Pesquisa-ação e educação: compartilhando princípios na construção de conhecimentos e no fortalecimento comunitário para o enfrentamento de problemas. Educação \& Sociedade, Campinas, v. 34, n. 122, p. 155-173, jan./mar. 2013.

TRIPP, David. Pesquisa ação: uma introdução metodológica. Tradução Lélio Lourenço de Oliveira. Educação e Pesquisa, São Paulo, v. 31, n. 3, p. 443-466, set./dez. 2005. 